\title{
Treadmill exercise ameliorates symptoms of Alzheimer disease through suppressing microglial activation- induced apoptosis in rats
}

\author{
Seung-Soo Baek*, Sang-Hoon Kim \\ Department of Sport \& Health Science, College of Natural Science, Sangmyung University, Seoul, Korea
}

Alzheimer disease (AD) is a most common form of dementia and eventually causes impairments of learning ability and memory function. In the present study, we investigated the effects of treadmill exercise on the symptoms of $A D$ focusing on the microglial activation-induced apoptosis. $A D$ was made by bilateral intracerebroventricular injection of streptozotocin. The rats in the exercise groups were made to run on a treadmill once a day for 30 min during 4 weeks. The distance and latency in the Morris water maze task and the latency in the step-down avoidance task were increased in the $A D$ rats, in contrast, treadmill exercise shortened these parameters. The numbers of terminal deoxynucleotidyl transferase-mediated dUTP nick end labeling-positive and caspase-3-positive cells in the hippocampal dentate gyrus were decreased in the $A D$ rats, in contrast, treadmill exercise suppressed these numbers. Expressions of glial fibrillary acidic protein (GFAP) and cluster of differentiation molecule 11B (CD11b) in the hippocampal dentate gyrus were increased in the $A D$ rats, in contrast, treadmill exercise suppressed GFAP and CD11b expressions. Bax expression was increased and $\mathrm{Bcl}-2$ expression was decreased in the hippocampus of $A D$ rats, in contrast, treadmill exercise decreased Bax expression and increased $\mathrm{Bcl}-2$ expression. The present results demonstrated that treadmill exercise ameliorated AD-induced impairments of spatial learning ability and short-term memory through suppressing apoptosis. The antiapoptotic effect of treadmill exercise might be ascribed to the inhibitory effect of treadmill exercise on microglial activation.

Keywords: Alzheimer disease, Apoptosis, Microglial activation, Rats

\section{INTRODUCTION}

Alzheimer disease (AD) gradually impairs learning ability and memory function (Sim, 2014), and the incidence of AD is 50\%$80 \%$ of dementia cases. The exact pathogenesis of $\mathrm{AD}$ is still not known. However, cerebral accumulation of amyloid- $\beta$ peptide, the primary component of senile plaques, has been suggested as the principal cause of AD pathogenesis (Selkoe, 2001). Intracerebroventricular (ICV) injection of streptozotocin (STZ) has been used for the animal model of $\mathrm{AD}$ (Jee et al., 2008).

Apoptosis in the hippocampus affects memory functions. Apoptosis has two main pathways (the extrinsic and intrinsic pathways). A class of cysteine proteases, such as caspase-8, caspase-9, and caspase- 3 , is commonly involved in these pathways
(Aggarwal, 2000) and caspase-3 is one of the most widely studied members of the caspase families and it is one of the key initiators of apoptosis (Fan et al., 2005). Furthermore, terminal deoxynucleotidyl transferase-mediated dUTP nick end labeling (TUNEL) staining is an assay that detects DNA fragmentation, which is the characteristic of apoptotic cell death (Kim et al., 2010). Caspase-3 expressions and the number of TUNEL-positive cells were enhanced in the hippocampus of $\mathrm{AD}$ and intracerebral hemorrhage rats (Lee et al., 2005; Song et al., 2014).

Besides caspases, the $\mathrm{Bcl}-2$ family proteins also play an important role in the regulation of apoptosis. The Bcl-2 family proteins are classified into antiapoptotic proteins, including $\mathrm{Bcl}-2$ and $\mathrm{Bcl}-$ 2XL, and pro-apoptotic proteins, such as Bax and Bid. The balance between pro-apoptotic and antiapoptotic Bcl-2 family mem-

\footnotetext{
*Corresponding author: Seung-Soo Baek (D) http://orcid.org/0000-0002-1340-2098 Department of Sport \& Health Science, College of Natural Science, Sangmyung University, 20 Hongjimun 2-gil, Jongno-gu, Seoul 03016, Korea Tel: +82-2-2287-5133, Fax: +82 -2-2287-0075, E-mail: ssoop@smu.ac.kr Received: October 27, 2016 / Accepted: December 1, 2016
}

This is an Open Access article distributed under the terms of the Creative Commons Attribution Non-Commercial License (http://creativecommons.org/licenses/by-nc/4.0/) which permits unrestricted non-commercial use, distribution, and reproduction in any medium, provided the original work is properly cited. 
bers determines the mitochondrial response to apoptotic stimuli (Upadhyay et al., 2003). The ratio of Bax to Bcl-2 was increased in the hippocampus of AD rats (Kitamura et al., 1998; Song et al., 2014).

Microglia are a type of glial cells that are the resident macrophages in the brain and spinal cord, thus microglia act as the first and main form of active immune defense mechanism in the central nervous system (Ransohoff and Perry, 2009). Activated microglial cells exert neurotoxic effect (Block et al., 2007) and increased microglial reactivity induces cellular apoptosis (Hooper and Pocock, 2007). Glial fibrillary acidic protein (GFAP) is an intermediate filament protein that is expressed in the numerous types of glial cells. Cluster of differentiation molecule 11B (CD11b) is the surface marker located on the plasma membrane of microglia. Expressions of GFAP and CD11b are used to identify glia cells and microglia, respectively (Singh et al., 2013; Sung et al., 2012).

Exercise is known to inhibit apoptosis and improves memory functions (Kim et al., 2014a; Kim et al., 2014b; Sim, 2014). However, the effects of treadmill exercise on $\mathrm{AD}$ in relation with microglial activation are not evaluated. In the present study, we investigated the effects of treadmill exercise on the microglial activation-induced apoptosis using streptozotocin-induced $\mathrm{AD}$ rats. For this study, Morris water maze task, step-down avoidance task, TUNEL assay, immunohistochemistry for caspase-3, GFAP, $\mathrm{CD} 11 \mathrm{~b}$, and western blot for $\mathrm{Bax}$ and $\mathrm{Bcl}-2$ were performed.

\section{MATERIALS AND METHODS}

\section{Animals and treatments}

Adult male Sprague-Dawley rats, weighing $400 \pm 20$ g (40 weeks old), were used for the experiments. The experimental procedures were performed in accordance with the animal care guidelines of the National Institutes of Health and the Korean Academy of Medical Sciences. The rats were housed under controlled temperature $\left(23^{\circ} \mathrm{C} \pm 2^{\circ} \mathrm{C}\right)$ and lighting $(08: 00$ a.m. to 20:00 p.m.) conditions with food and water available ad libitum. The animals were randomly divided into four groups ( $\mathrm{n}=10$ in each group): sham-operation group, sham-operation and treadmill exercise group, AD-induced group, and AD-induced and treadmill exercise group.

\section{Induction of $A D$}

$\mathrm{AD}$ was induced according to the previously described method (Jee et al., 2008; Sim, 2014). The rats were anesthetized with Zo- letil 50 (10 mg/kg, intraperitoneally; Vibac Laboratories, Carros, France) and placed in a stereotaxic frame. Burr holes were drilled in the skull on both sides over the lateral ventricles using the following coordinates: $0.8 \mathrm{~mm}$ posterior to bregma, $1.5 \mathrm{~mm}$ lateral to sagittal suture, and $3.6 \mathrm{~mm}$ beneath the surface of brain. Through a hole drilled in the skull, a 26-gauge needle was lowered manually into each lateral ventricle. The rats in the AD-induced groups received bilateral ICV injection of STZ $(1.5 \mathrm{mg} / \mathrm{kg}$, $5 \mu \mathrm{L}$ in saline). The rats in the sham-operation group underwent the same surgical procedures, but same volume of saline was injected instead of STZ.

\section{Exercise protocol}

The rats in the exercise groups were forced to run on a motorized treadmill. The rats in the exercise groups were made to run on a treadmill once a day for 30 min during 4 weeks, starting 3 days after STZ injection. The exercise load consisted of running at the speed of $8 \mathrm{~m} / \mathrm{min}$ with a $0^{\circ}$ inclination.

\section{Morris water maze task}

Spatial learning ability was determined using Morris water maze task, according to the previously described method (Heo et al., 2014). The water maze was a black circular pool (diameter, $140 \mathrm{~cm}$; height, $45 \mathrm{~cm}$ ) filled with water (room temperature) and positioned in a room with many visual cues. On the 21 days after starting exercise, the rats were trained on a water maze, with two trials per day for 5 days. Each trial lasted either until the rats had found the platform or for a maximum of $3 \mathrm{~min}$. At the end of each trial, the rats were allowed to rest on the platform (diameter, $15 \mathrm{~cm}$; height, $35 \mathrm{~cm}$ ) submerged $2 \mathrm{~cm}$ below the water surface for $15 \mathrm{sec}$. If the rats were unable to locate the platform within 3 min, they were guided to the platform and left there for $15 \mathrm{sec}$ before being removed from the pool. The length of the swim path (distance) and the time to reach the platform (latency) were recorded by a video racking system (Smart version 2.5, Panlab, Barcelona, Spain).

\section{Step-down avoidance task}

The latency in the step-down avoidance task was determined to evaluate the short-term memory, according to the previously described method (Jin et al., 2014). The rats were trained in a stepdown avoidance task on the 28 days after starting the treadmill exercise. The rats were placed on a $7 \times 25-\mathrm{cm}$ platform which was $2.5 \mathrm{~cm}$ in height. The platform faced a $42 \times 25-\mathrm{cm}$ grid of parallel stainless steel bars, $0.1 \mathrm{~cm}$ in caliber, spaced $1 \mathrm{~cm}$ apart. In the 
training sessions, the animals received a $0.5-\mathrm{mA}$ scramble foot shock for 2 sec immediately upon stepping down. Two hours after training, the latency (sec) in each group was measured. The interval of time which elapsed between the rats stepping down and placing all four paws on the grid was defined as the latency. Latency over $300 \mathrm{sec}$ was counted as $300 \mathrm{sec}$.

\section{Tissue preparation}

The animals were sacrificed immediately after determining the latency in the step-down avoidance task. The rats were anesthetized using Zoletil $50(10 \mathrm{mg} / \mathrm{kg}$, intraperitoneally; Vibac Laboratories), transcardially perfused with 50-mM phosphate-buffered saline (PBS), and fixed with a freshly prepared solution consisting of $4 \%$ paraformaldehyde in $100-\mathrm{mM}$ phosphate buffer $(\mathrm{pH}, 7.4)$. Brains were dissected, and storage overnight same fixative, then it was transferred to $30 \%$ sucrose for cryoprotection. The slices were coronal sectioned at $40 \mu \mathrm{m}$ thick using a cryostat (Leica, Nussloch, Germany). Ten slice sections on average in the hippocampal dentate gyrus were collected from each rat.

\section{TUNEL assay}

To visualize DNA fragmentation, TUNEL staining was performed using an In Situ Cell Death Detection Kit (Roche, Mannheim, Germany), according to the previously described method (Lee et al., 2005). The sections were post-fixed in ethanol-acetic acid (2:1) and rinsed. The sections were then incubated with proteinase $\mathrm{K}(100 \mu \mathrm{g} / \mathrm{mL})$, rinsed, and incubated in $3 \% \mathrm{H}_{2} \mathrm{O}_{2}$, permeabilized with $0.5 \%$ Triton X-100, rinsed again, and incubated in the TUNEL reaction mixture. The sections were rinsed and visualized using Converter-POD with $0.03 \%$ 3,3'-diaminobenzidine (DAB). Mayer's hematoxylin (DAKO, Glostrup, Denmark) was used as a counter-stain, and the sections were mounted onto gelatin-coated slides. The slides were air-dried overnight at room temperature and dehydrated through a gradient of ethanol and covered with coverslips using Permount (Fisher Scientific, New Jersey, NJ, USA).

\section{Immunohistochemistry for caspase-3, GFAP, and CD11 b}

To detect apoptosis and microglial activation, immunohistochemistry for caspase-3, GFAP, and CD11b was performed, according to the previously described method (Choi et al., 2013; Kim et al., 2014b; Sung et al., 2012). The sections were drawn from each brain and incubated overnight with mouse anti-caspase- 3 , rabbit anti-GFAP, and mouse anti-CD11b antibody (1:500; Santa Cruz Biotechnology, Santa Cruz, CA, USA). The sections were then washed three times with PBS and incubated for $1 \mathrm{hr}$ with biotinylated anti-mouse caspase, anti-rabbit GFAP and, anti-mouse CD11b secondary antibody (1:200; Vector Laboratories, Burlingame, CA, USA). Bound secondary antibody was then amplified with Vector Elite ABC kit (1:100; Vector Laboratories). The antibody-biotin-avidin-peroxidase complexes were visualized using $0.03 \% \mathrm{DAB}$ and the sections were finally mounted onto gelatin-coated slides. The slides were air dried overnight at room temperature, and coverslips were mounted using Permount (Fisher Scientific).

\section{Western blotting for Bax and Bcl-2}

Bax and Bcl-2 expressions were determined by Western blot analysis, according to the previously described method (Kim et al., 2010). The hippocampal tissues were dissected and collected, and then were immediately frozen at $-70^{\circ} \mathrm{C}$. The hippocampal tissues were homogenized on ice, and lysed in a lysis buffer containing 50-mM HEPES (N-2-hydroxyethylpiperazine-N-2-ethanesulfonic acid) (pH, 7.5), 150-mM NaCl, $10 \%$ glycerol, $1 \%$ Triton X-100, 1-mM PMSF (phenylmethylsulfonyl fluoride), 1-mM EGTA (ethyleneglycol-bis-(b-aminoethylether)-N,N,N', $\mathrm{N}$-tetraacetic acid), 1.5-mM MgCl $2 \cdot 6 \mathrm{H}_{2} \mathrm{O}, 1-\mathrm{mM}$ sodium orthovanadate, and 100-mM sodium fluoride. Protein content was measured using a Bio-Rad colorimetric protein assay kit (Hercules, CA, USA). Protein samples ( $30 \mu \mathrm{g}$ ) were separated on sodium dodecyl sulfate-polyacrylamide gel and transferred onto a nitrocellulose membrane. The membranes were incubated with $5 \%$ skim milk in Tris-buffered saline containing 0.1\% Tween-20 and then incubated overnight at $4^{\circ} \mathrm{C}$ with the following primary antibodies: mouse anti- $\beta$-actin, mouse anti-Bcl-2, and mouse anti-Bax (1:1,000; Santa Cruz Biotechnology). Subsequently, membranes were incubated for $1 \mathrm{hr}$ with attempt secondary antibodies (1:2,000; Vector Laboratories), and band detection was performed using the enhanced chemiluminescence detection kit (Santa Cruz Biotechnology).

\section{Statistical analysis}

For the confirmation of the expression of apoptotic proteins, the detected bands were calculated densitometrically using Molecular Analyst ver. 1.4.1 (Bio-Rad). The numbers of TUNEL-positive and caspase-3-positive cells in the hippocampal dentate gyrus were counted hemilaterally under a light microscope (Olympus, Tokyo, Japan), and they were expressed as the numbers of cells/ $\mathrm{mm}^{2}$ of the dentate gyrus area. The area of the dentate gyrus region was measured by Image-Pro Plus image analysis system (Me- 
dia Cyberbetics Inc., Silver Spring, MD, USA). The optical densities of GFAP and CD11b immunoreactive fibers were measured in $100 \mu \mathrm{m} \times 100 \mu \mathrm{m}$ square images in the hippocampal dentate gyrus using an image analyzer (Multiscan, Fullerton, CA, USA). To estimate the GFAP and CD11b staining densities, the optical densities were corrected for the nonspecific background density, which was measured in the completely denervated parts of the hippocampal dentate gyrus. The GFAP-positive and CD11b-positive fiber densities were calculated as follows: the optical density

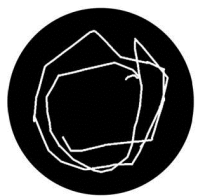

Sham

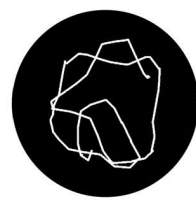

Sham-EX

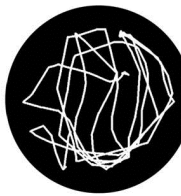

AD

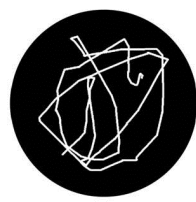

AD-EX
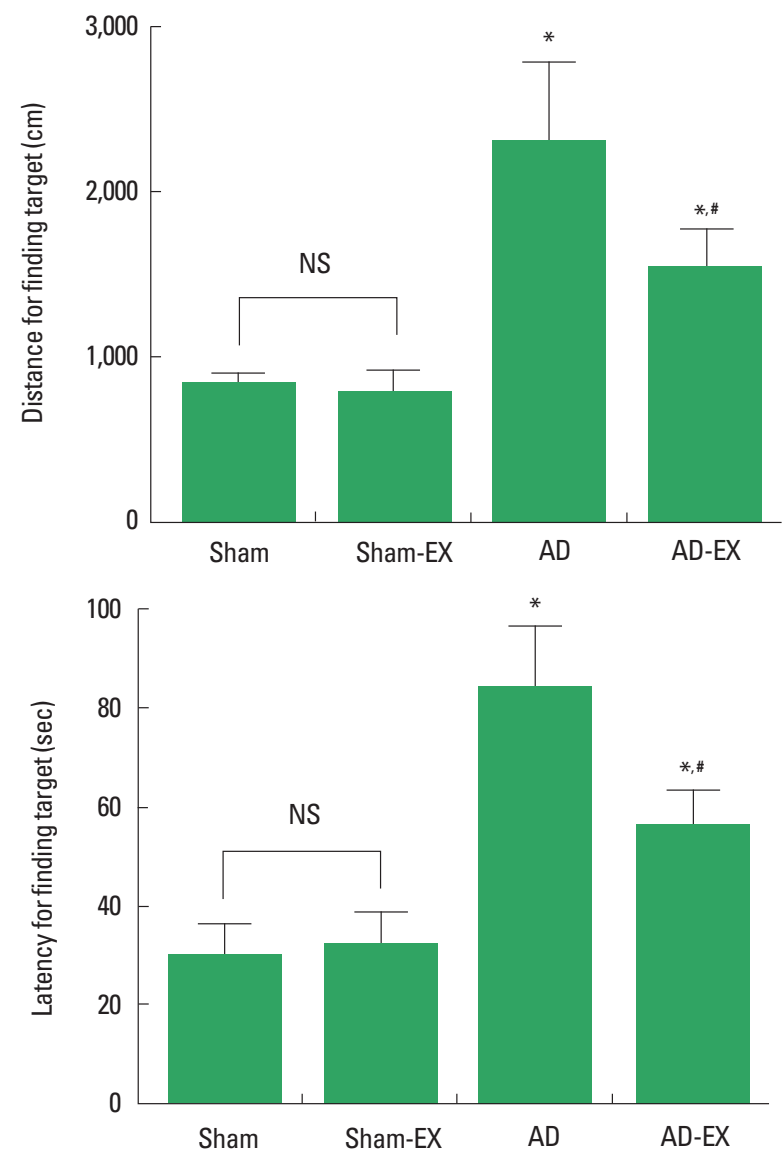

Fig. 1. Spatial learning ability in the Morris water maze task. Upper panel: Swimming path; Lower panel: Distance and latency. The data represent mean standard error of the mean. Sham, Sham-operation group; Sham-EX, sham-operation and treadmill exercise group; $A D$, Alzheimer disease-induced group; AD-EX, Alzheimer disease-induced and treadmill exercise group; NS, nonsignificant. ${ }^{*} P<0.05$ compared to the sham-operation group. ${ }^{\sharp} P<0.05$ compared to the Alzheimer disease-induced group. in the lesion side/the optical density in the intact side.

Statistical analysis was performed using one-way analysis of variance followed by Duncan post hoc test, and the results are expressed as the mean \pm standard error of the mean. Significance was set as $P<0.05$.

\section{RESULTS}

\section{Effect of treadmill exercise on the spatial learning ability}

AD-induced rats showed increase of distance and latency for finding target than those in the sham-operation group. In other hand, treadmill exercise reduced the distance and latency in the $\mathrm{AD}$ rats (Fig. 1).

\section{Effect of treadmill exercise on the short-term memory}

$\mathrm{AD}$-induced rats showed decrease of latency time than those in the sham-operation group. In other hand, treadmill exercise increased the latency time in the $\mathrm{AD}$ rats (Fig. 2).

\section{Effect of treadmill exercise on the DNA fragmentation in the hippocampal dentate gyrus}

AD-induced rats showed enhanced DNA fragmentation in the hippocampal dentate gyrus than those in the sham-operation group. In other hand, treadmill exercise suppressed the DNA fragmentation in the $\mathrm{AD}$ rats (Fig. 3).

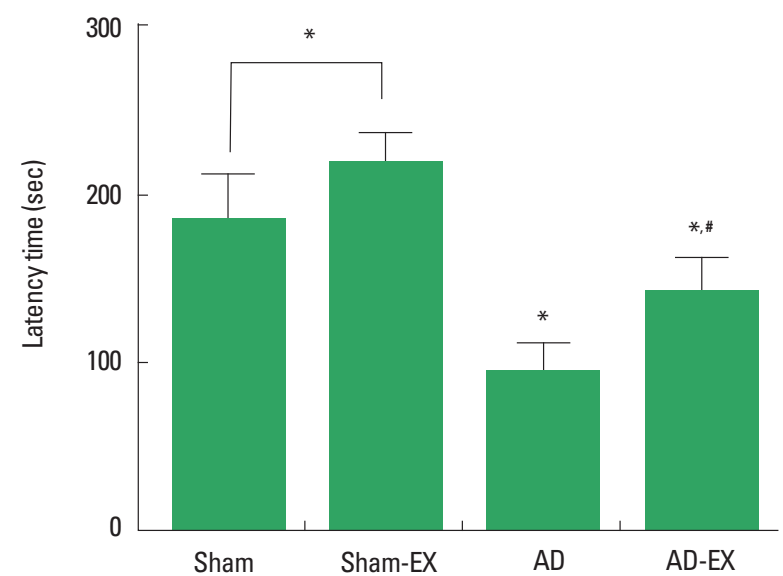

Fig. 2. Short-term memory in the step-down avoidance task. The data represent mean standard error of the mean. Sham, Sham-operation group; Sham-EX, sham-operation and treadmill exercise group; AD, Alzheimer disease-induced group; AD-EX, Alzheimer disease-induced and treadmill exercise group; NS, nonsignificant. ${ }^{*} P<0.05$ compared to the sham-operation group. ${ }^{\#} P<0.05$ compared to the Alzheimer disease-induced group. 

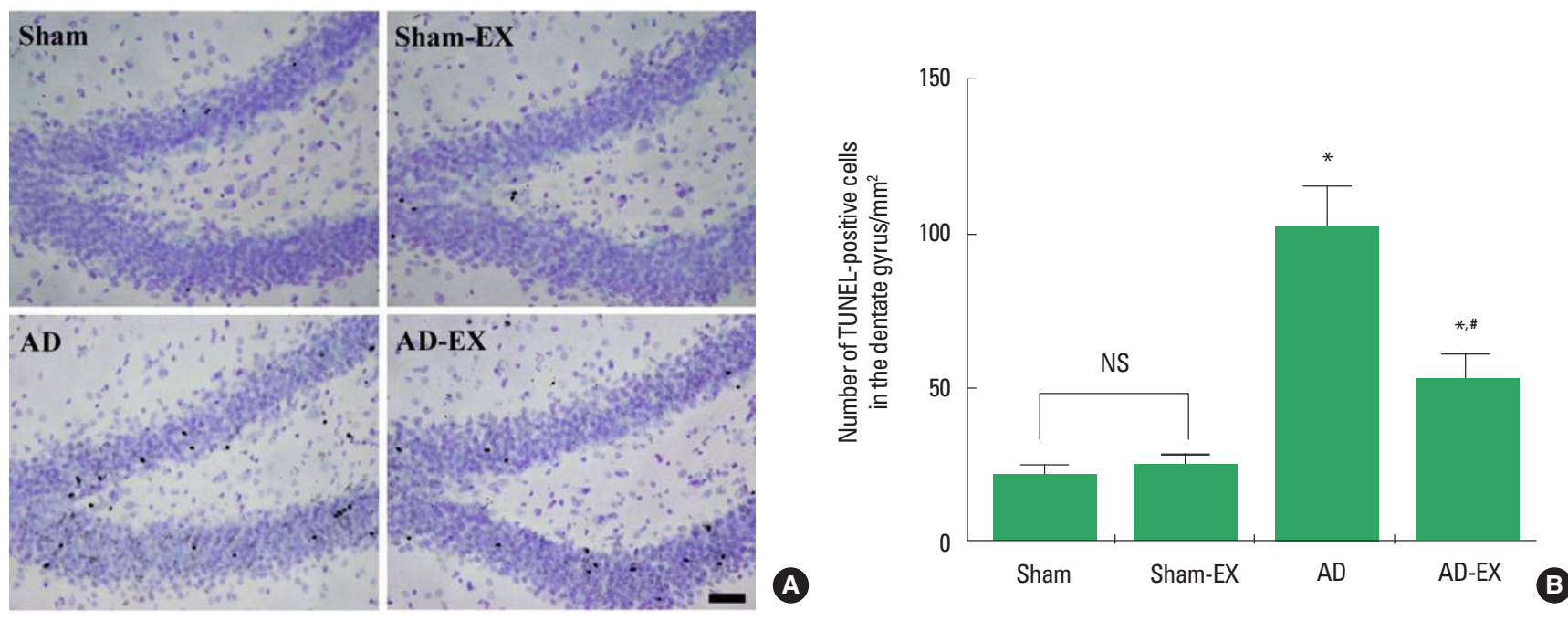

Fig. 3. DNA fragmentation in the hippocampal dentate gyrus. (A) Photomicrographs of terminal deoxynucleotidyl transferase-medi-ated dUTP nick end labeling (TUNEL)-positive cells in the hippocampal dentate gyrus. The scale bars represent $25 \mu \mathrm{m}$. (B) Number of TUNEL-positive cells in each group. The data represent mean standard error of the mean. Sham, Sham-operation group; Sham-EX, sham-operation and treadmill exercise group; AD, Alzheimer disease-induced group; AD-EX, Alzheimer disease-induced and treadmill exercise group; NS, nonsignificant. ${ }^{*} P<0.05$ compared to the sham-operation group. ${ }^{\#} P<0.05$ compared to the Alzheimer disease-induced group.
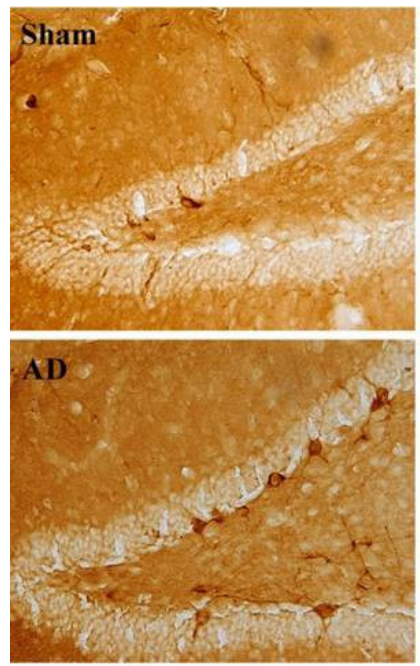
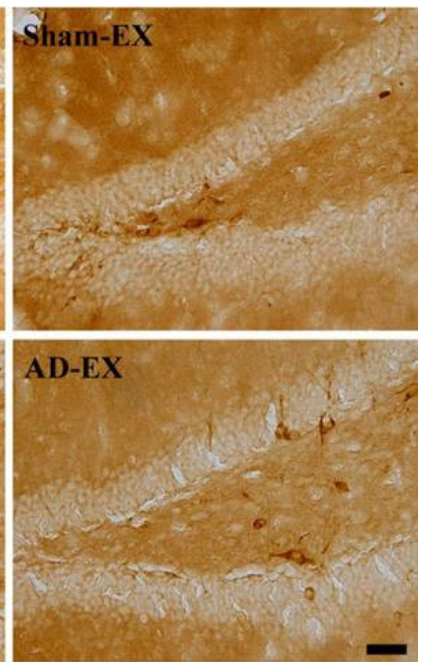

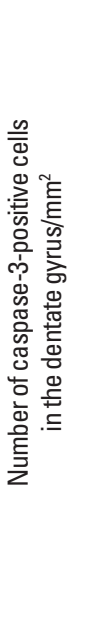

Fig. 4. Caspase-3 expression in the hippocampal dentate gyrus. (A) Photomicrographs of caspase-3-positive cells in the hippocampal dentate gyrus. The scale bars represent $25 \mu \mathrm{m}$. (B) Number of caspase-3-positive cells in each group. The data represent mean standard error of the mean. Sham, Sham-operation group; Sham-EX, sham-operation and treadmill exercise group; AD, Alzheimer disease-induced group; AD-EX, Alzheimer disease-induced and treadmill exercise group; NS, nonsignificant. ${ }^{*} P<0.05$ compared to the sham-operation group. ${ }^{\sharp} P<0.05$ compared to the Alzheimer disease-induced group.

\section{Effect of treadmill exercise on the caspase-3 expression in the hippocampal dentate gyrus}

AD-induced rats showed enhanced caspase- 3 expression in the hippocampal dentate gyrus than those in the sham-operation group. In other hand, treadmill exercise suppressed the caspase-3 expression in the $\mathrm{AD}$ rats (Fig. 4).

\section{Effect of treadmill exercise on the GFAP expression in the hippocampal dentate gyrus}

AD-induced rats showed enhanced GFAP expression in the hippocampal dentate gyrus than those in the sham-operation group. In other hand, treadmill exercise suppressed the GFAP expression in the $\mathrm{AD}$ rats (Fig. 5). 

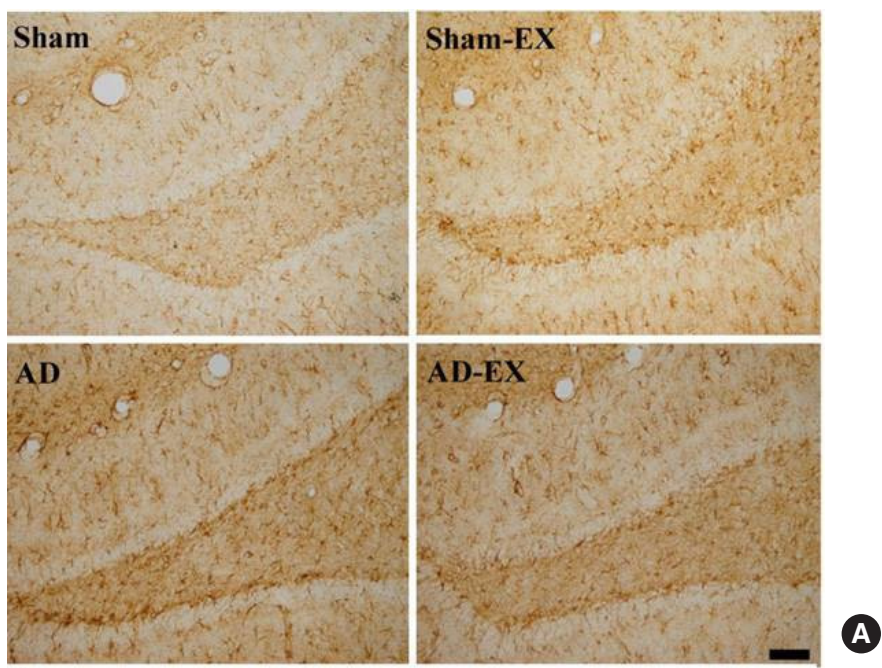

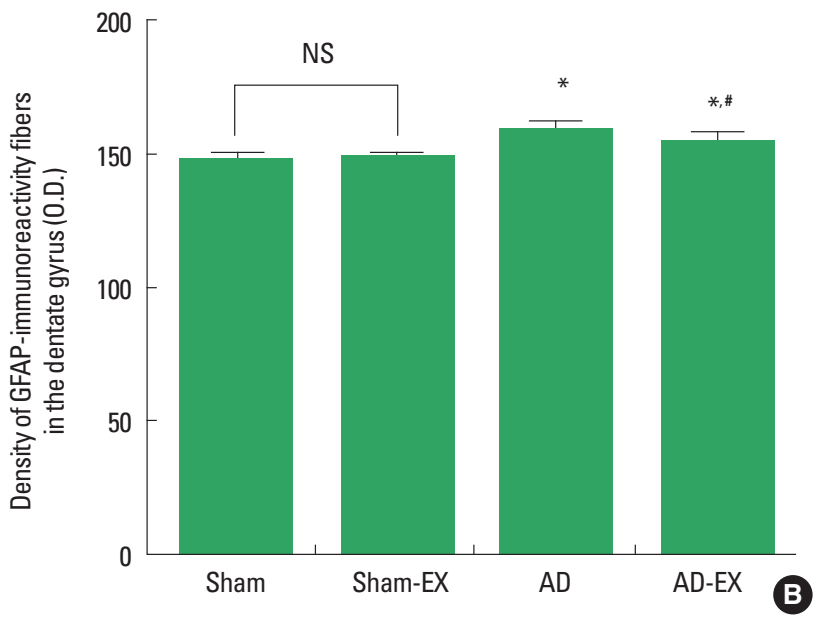

Fig. 5. Glial fibrillary acidic protein (GFAP) expression in the hippocampal dentate gyrus. (A) Photomicrographs of GFAP-positive fibers in the hippocampal dentate gyrus. The scale bars represent $25 \mu \mathrm{m}$. (B) Optical density of GFAP-positive fibers in each group. The data represent mean standard error of the mean. Sham, Sham-operation group; Sham-EX, sham-operation and treadmill exercise group; AD, Alzheimer disease-induced group; AD-EX, Alzheimer disease-induced and treadmill exercise group; NS, nonsignificant. ${ }^{*} P<0.05$ compared to the sham-operation group. ${ }^{\#} P<0.05$ compared to the Alzheimer disease-induced group.
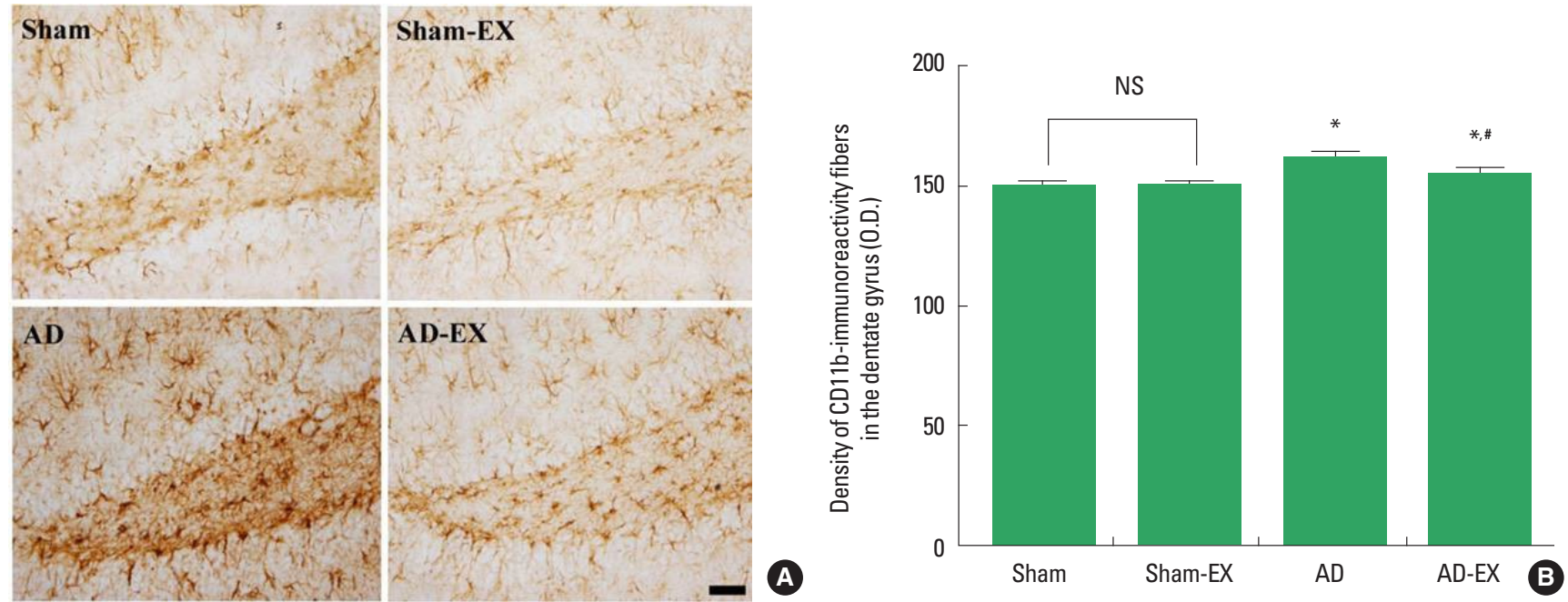

Fig. 6. Cluster of differentiation molecule 11B (CD11b) expression in the hippocampal dentate gyrus. (A) Photomicrographs of CD11b-positive fibers in the hippocampal dentate gyrus. The scale bars represent $25 \mu \mathrm{m}$. (B) Optical density of CD11b-positive fibers in each group. The data represent mean standard error of the mean. Sham, Sham-operation group; Sham-EX, sham-operation and treadmill exercise group; AD, Alzheimer disease-induced group; AD-EX, Alzheimer disease-induced and treadmill exercise group; NS, nonsignificant. ${ }^{*} P<0.05$ compared to the sham-operation group. ${ }^{*} P<0.05$ compared to the Alzheimer disease-induced group.

\section{Effect of treadmill exercise on the CD11b expression in the hippocampal dentate gyrus}

$\mathrm{AD}$-induced rats showed enhanced $\mathrm{CD} 11 \mathrm{~b}$ expression in the hippocampal dentate gyrus than those in the sham-operation group. In other hand, treadmill exercise suppressed the CD11b expression in the AD rats (Fig. 6).

\section{Effect of treadmill exercise on the Bax and Bcl-2 expressions in the hippocampus}

AD-induced rats showed enhanced Bax expression and decreased $\mathrm{Bcl}-2$ expression, therefore, induction of $\mathrm{AD}$ enhanced $\mathrm{Bax}$ to $\mathrm{Bcl}-2$ ratio. In other hand, treadmill exercise suppressed Bax expression and increased $\mathrm{Bcl}-2$ expression, resulting in decrease of Bax to Bcl-2 ratio (Fig. 7). 

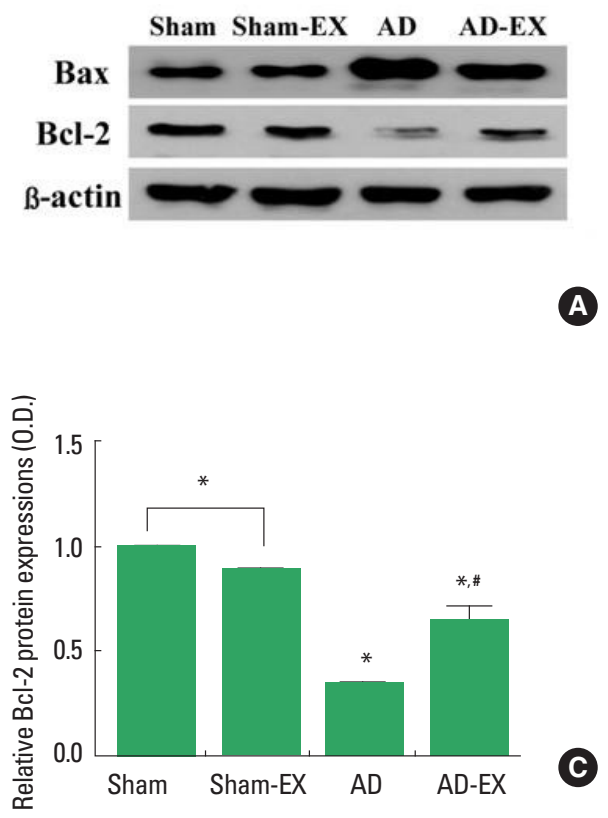

C
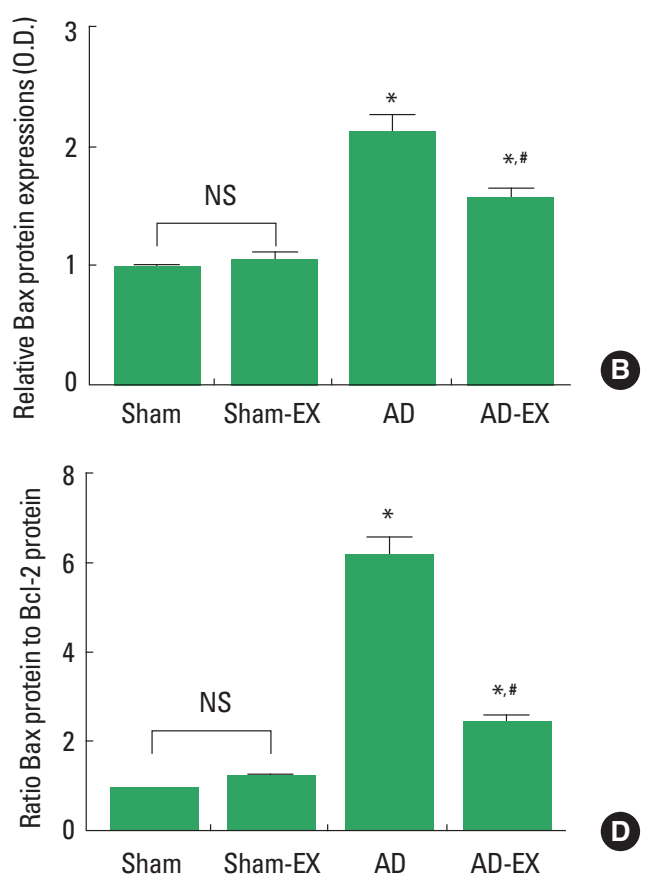

Fig. 7. Bax and Bcl-2 expression in the hippocampal dentate gyrus. (A) Western blot analysis. (B) Bax expression in the hippocampus. (C) Bcl-2 expression in the hippocampus. (D) Bax to Bcl-2 ratio. The data represent mean standard error of the mean. Sham, Sham-operation group; Sham-EX, sham-operation and treadmill exercise group; AD, Alzheimer disease-induced group; AD-EX, Alzheimer disease-induced and treadmill exercise group; NS, nonsignificant. ${ }^{*} P<0.05$ compared to the sham-operation group. ${ }^{\#} P<0.05$ compared to the Alzheimer disease-induced group.

\section{DISCUSSION}

Injection of STZ into the ventricles caused structural alterations and physiological impairments of the hippocampus, and such changes contribute to memory impairments (Jee et al., 2008; Muller et al., 2012). Injection of STZ in rats induced desensitization of insulin receptors and biochemical changes, such as glucose and energy metabolism (Muller et al., 2012). In the present study, the distance and latency in the Morris water maze task were shortened and the latency in the step-down avoidance task was also shortened by injection of STZ in rats. Treadmill exercise increased the distance and latency of the Morris water maze task and also increased the latency of the step-down avoidance task in the $\mathrm{AD}$ rats. The present results represent that treadmill exercise ameliorated $\mathrm{AD}$-induced deterioration of spatial learning ability and short-term memory.

Caspase- 3 is one of the most widely studies members of the caspase family and it is involved in apoptosis as the principal executor (Jin et al., 2014; Ko et al., 2009; Martin et al., 2002). Furthermore, caspase- 3 is up-regulated and activated in the early-stage of apoptosis (Benchoua et al., 2001; Kang et al., 2013). TUNEL assay is a common method for detecting DNA fragmentation that is the hallmark of apoptosis (Choi et al., 2013; Ji et al., 2013; Jin et al., 2014). In the present study, expression of caspase- 3 and the number of TUNEL-positive cells in the hippocampal dentate gyrus were enhanced in the $\mathrm{AD}$ rats. Treadmill exercise suppressed caspase-3 expression and the number of TUNEL-positive cells in the $\mathrm{AD}$ rats, showing that treadmill exercise inhibited $\mathrm{AD}$-induced apoptotic cell death in the hippocampus.

The Bcl-2 family includes anti-apoptotic molecules, Bcl-2, and pro-apoptotic molecules, $\mathrm{Bax}, \mathrm{Bid}$, and $\mathrm{Bad}$. The $\mathrm{Bcl}-2$ family is critical factor in determining whether neurons survive or die (Cory et al., 2003). Increased Bax expression and decreased Bcl-2 expression were observed in the AD (Kitamura et al., 1998; Song et al., 2014; Um et al., 2011). In the present study, the expression of $\mathrm{Bax}$ was increased and the expression of $\mathrm{Bcl}-2$ was decreased, as a result, the ratio of $\mathrm{Bax}$ to $\mathrm{Bcl}-2$ was enhanced in the $\mathrm{AD}$ rats. Treadmill exercise suppressed Bax expression and enhanced $\mathrm{Bcl}-2$ expression, thus the ratio of $\mathrm{Bax}$ to $\mathrm{Bcl}-2$ was decreased in the $\mathrm{AD}$ rats. These results also showed that treadmill exercise inhibited AD-induced apoptotic cell death in the hippocampus.

Inflammation and microglial activation are implicated in the pathogenesis of $\mathrm{AD}$ (Bamberger and Ladreth, 2002; Cameron and Landreth, 2010). Enhanced GFAP and CD11b expressions represent microglial activation in AD (Ruan et al., 2009; Sung et al., 2012). In the present study, GFAP and CD11b expressions were increased in the AD rats. Treadmill exercise decreased GFAP and $\mathrm{CD} 11 \mathrm{~b}$ expressions in the $\mathrm{AD}$ rats, representing that treadmill exercise suppressed AD-induced microglial activation in the hippocampus.

The present results showed that treadmill exercise ameliorated AD-induced impairments of spatial learning ability and short- 
term memory through suppressing apoptosis. The antiapoptotic effect of treadmill exercise might be ascribed to the inhibitory effect of treadmill exercise on microglial activation. According to these effects of treadmill exercise, treadmill exercise may be suggested as a useful strategy for symptom improvement of several neurodegenerative diseases, including AD.

\section{CONFLICT OF INTEREST}

No potential conflict of interest relevant to this article was reported.

\section{ACKNOWLEDGMENTS}

This work was supported by the 2015 Research Grant of Sangmyung University.

\section{REFERENCES}

Aggarwal BB. Apoptosis and nuclear factor-kappa B: a tale of association and dissociation. Biochem Pharmacol 2000;60:1033-1039.

Bamberger ME, Landreth GE. Inflammation, apoptosis, and Alzheimer's disease. Neuroscientist 2002;8:276-283.

Benchoua A, Guégan C, Couriaud C, Hosseini H, Sampaïo N, Morin D, Onténiente B. Specific caspase pathways are activated in the two stages of cerebral infarction. J Neurosci 2001;21:7127-7134.

Block ML, Zecca L, Hong JS. Microglia-mediated neurotoxicity: uncovering the molecular mechanisms. Nat Rev Neurosci 2007;8:57-69.

Cameron B, Landreth GE. Inflammation, microglia, and Alzheimer's disease. Neurobiol Dis 2010;37:503-509.

Choi JH, Kim TS, Park JK, Sim YJ, Kim K, Lee SJ. Short-term treadmill exercise preserves sensory-motor function through inhibiting apoptosis in the hippocampus of hypoxic ischemia injury rat pups. J Exerc Rehabil 2013;9:457-462.

Cory S, Huang DC, Adams JM. The Bcl-2 family: roles in cell survival and oncogenesis. Oncogene 2003;22:8590-8607.

Fan TJ, Han LH, Cong RS, Liang J. Caspase family proteases and apoptosis. Acta Biochim Biophys Sin (Shanghai) 2005;37:719-727.

Heo YM, Shin MS, Kim SH, Kim TW, Baek SB, Baek SS. Treadmill exercise ameliorates disturbance of spatial learning ability in scopolamine-induced amnesia rats. J Exerc Rehabil 2014;10:155-161.

Hooper C, Pocock JM. Chromogranin A activates diverse pathways mediating inducible nitric oxide expression and apoptosis in primary microglia. Neurosci Lett 2007;413:227-232.

Jee YS, Ko IG, Sung YH, Lee JW, Kim YS, Kim SE, Kim BK, Seo JH, Shin
MS, Lee HH, Cho HJ, Kim CJ. Effects of treadmill exercise on memory and c-Fos expression in the hippocampus of the rats with intracerebroventricular injection of streptozotocin. Neurosci Lett 2008;443:188192.

Ji ES, Ko IG, Cho JW, Davis RW, Hwang GY, Jee YS, Lim BV. Treadmill exercise inhibits apoptotic neuronal cell death with suppressed vascular endothelial growth factor expression in the retinas of the diabetic rats. J Exerc Rehabil 2013;9:348-353.

Jin JJ, Ko IG, Kim SE, Shin MS, Kim SH, Jee YS. Swimming exercise ameliorates multiple sclerosis-induced impairment of short-term memory by suppressing apoptosis in the hippocampus of rats. J Exerc Rehabil 2014;10:69-74.

Kang EB, Kwon IS, Koo JH, Kim EJ, Kim CH, Lee J, Yang CH, Lee YI, Cho $\mathrm{IH}$, Cho JY. Treadmill exercise represses neuronal cell death and inflammation during $\mathrm{A} \beta$-induced ER stress by regulating unfolded protein response in aged presenilin 2 mutant mice. Apoptosis 2013;18: 1332-1347.

Kim BK, Shin MS, Kim CJ, Baek SB, Ko YC, Kim YP. Treadmill exercise improves short-term memory by enhancing neurogenesis in amyloid beta-induced Alzheimer disease rats. J Exerc Rehabil 2014a;10:2-8.

Kim K, Shin MS, Cho HS, Kim YP. Effects of endurance exercise on expressions of glial fibrillary acidic protein and myelin basic protein in developing rats with maternal infection-induced cerebral palsy. J Exerc Rehabil 2014b;10:9-14.

Kim SE, Ko IG, Kim BK, Shin MS, Cho S, Kim CJ, Kim SH, Baek SS, Lee $\mathrm{EK}$, Jee YS. Treadmill exercise prevents aging-induced failure of memory through an increase in neurogenesis and suppression of apoptosis in rat hippocampus. Exp Gerontol 2010;45:357-365.

Kitamura Y, Shimohama S, Kamoshima W, Ota T, Matsuoka Y, Nomura Y, Smith MA, Perry G, Whitehouse PJ, Taniguchi T. Alteration of proteins regulating apoptosis, Bcl-2, Bcl-x, Bax, Bak, Bad, $\mathrm{ICH}-1$ and CPP32, in Alzheimer's disease. Brain Res 1998;780:260-269.

Ko IG, Shin MS, Kim BK, Kim SE, Sung YH, Kim TS, Shin MC, Cho HJ, Kim SC, Kim SH, Kim KH, Shin DH, Kim CJ. Tadalafil improves short-term memory by suppressing ischemia-induced apoptosis of hippocampal neuronal cells in gerbils. Pharmacol Biochem Behav 2009;91:629-635.

Lee HH, Shin MS, Kim YS, Yang HY, Chang HK, Lee TH, Kim CJ, Cho S, Hong SP. Early treadmill exercise decreases intrastriatal hemorrhage-induced neuronal cell death and increases cell proliferation in the dentate gyrus of streptozotocin-induced hyperglycemic rats. J Diabetes Complications 2005;19:339-346.

Martin DS, Lonergan PE, Boland B, Fogarty MP, Brady M, Horrobin DF, Campbell VA, Lynch MA. Apoptotic changes in the aged brain are triggered by interleukin-1beta-induced activation of $\mathrm{p} 38$ and reversed 
by treatment with eicosapentaenoic acid. J Biol Chem 2002;277:3423934246.

Muller AP, Zimmer ER, Kalinine E, Haas CB, Oses JP, Martimbianco de Assis A, Galina A, Souza DO, Portela LV. Physical exercise exacerbates memory deficits induced by intracerebroventricular STZ but improves insulin regulation of $\mathrm{H}_{2} \mathrm{O}_{2}$ production in mice synaptosomes. J Alzheimers Dis 2012;30:889-898.

Ransohoff RM, Perry VH. Microglial physiology: unique stimuli, specialized responses. Annu Rev Immunol 2009;27:119-145.

Ruan L, Kang Z, Pei G, Le Y. Amyloid deposition and inflammation in APPswe/PS1dE9 mouse model of Alzheimer's disease. Curr Alzheimer Res 2009;6:531-540.

Selkoe DJ. Clearing the brain's amyloid cobwebs. Neuron 2001;32:177180.

Sim YJ. Treadmill exercise alleviates impairment of spatial learning ability through enhancing cell proliferation in the streptozotocin-induced Alzheimer's disease rats. J Exerc Rehabil 2014;10:81-88.

Singh A, Falk MK, Hviid TV, Sørensen TL. Increased expression of CD200 on circulating $\mathrm{CD} 11 \mathrm{~b}+$ monocytes in patients with neovascular age-related macular degeneration. Ophthalmology 2013;120:1029-1037.

Song J, Hur BE, Bokara KK, Yang W, Cho HJ, Park KA, Lee WT, Lee KM, Lee JE. Agmatine improves cognitive dysfunction and prevents cell death in a streptozotocin-induced Alzheimer rat model. Yonsei Med J 2014;55:689-699.

Sung YH, Kim SC, Hong HP, Park CY, Shin MS, Kim CJ, Seo JH, Kim DY, Kim DJ, Cho HJ. Treadmill exercise ameliorates dopaminergic neuronal loss through suppressing microglial activation in Parkinson's disease mice. Life Sci 2012;91:1309-1316.

Um HS, Kang EB, Koo JH, Kim HT, Jin-Lee, Kim EJ, Yang CH, An GY, Cho IH, Cho JY. Treadmill exercise represses neuronal cell death in an aged transgenic mouse model of Alzheimer's disease. Neurosci Res 2011;69:161-173.

Upadhyay D, Panduri V, Ghio A, Kamp DW. Particulate matter induces alveolar epithelial cell DNA damage and apoptosis: role of free radicals and the mitochondria. Am J Respir Cell Mol Biol 2003;29:180-187. 